\title{
Abortion Effect in Corals Induced by Oil Pollution
}

\author{
Y. Loya and B. Rinkevich \\ The George S. Wise Center for Life Sciences, Department of Zoology, \\ Tel Aviv University, Tel Aviv, Israel
}

\begin{abstract}
Sublethal concentrations of Iranian crude oil induce immediate mouth-opening in the Red Sea coral Stylophora pistillata, followed by premature extrusion of planulae larvae. Laboratory experiments with different concentrations of water soluble fractions (WSF) of Iranian crude oil $\left(0.1-10.0 \mathrm{ml}^{-1}\right)$, showed that the average number of planulae extruded in each oil concentration was significantly higher than in the control. In natural conditions S. pistillata sheds its planulae only during the night. In presence of WSF of crude oil, shedding is immediate, day or night. Shedding of planulae during an oil spill decreases their viability and chances of successful settlement. In chronically oil-polluted reefs, such as the coral nature reserve of Eilat, almost no colonization of new coral colonies occurs, while high colonization is evident in reef areas free of oil pollution.
\end{abstract}

\section{INTRODUCTION}

Oil pollution of the seas is currently a world wide environmental problem ('Marine Ecology', Volume $\mathrm{V}$. Kinne, in press), and coral reefs are increasingly exposed to it (see reviews by Johannes, 1975; Loya and Rinkevich, in press). The scleractinian corals are a key group in forming coral reefs and providing substrate and shelter for many invertebrates and fishes. Acute damage to the corals may result in a collapse of the complex community of organisms which are in close association with the corals.

In previous works, Loya $(1975,1976 a)$ noted that no colonization of corals occurred on the reef flats of the nature reserve of Eilat which is chronically polluted by oil, while a pollution-free control reef was flourishing with high diversity of newly settled corals. He suggested that the frequent oil spills around the nature reserve of Eilat resulted in either one or a combination of the following possibilities: (1) damage to the reproductive system of corals; (2) decreased viability of coral larvae; (3) changes in some physical properties of the reef flat which interfere with normal settlement of coral larvae. These possibilities were further investigated by Rinkevich and Loya (1977) on populations of the coral Stylophora pistillata (Esper) in the field (chronically oil-polluted area vs. clean reef) and laboratory. The coral population at the oil-polluted reef showed higher mortality rates of colonies, smaller numbers of breeding colonies, a decrease in the average number of ovaria per polyp, smaller numbers of planulae produced per coral head (fecundity was 4 times higher in the clean reef), and lower settlement rates of planulae on artificial objects.

The branched scleractinian coral Stylophora pistillata is one of the most abundant coral species in the shallow waters of the Gulf of Eilat, Red Sea, and is among the most important frame builders of the reef flat (Loya, 1972). Some aspects of the life history of this species were studied including its reproductive biology (Rinkevich and Loya, 1979a, b), development and growth rate, regeneration rate, population dynamics (Loya, 1976b, c) and oil pollution effects on its population (Rinkevich and Loya, 1977).

In this paper we describe an abortion effect in populations of Stylophora pistillata induced by crude oil, which causes untimely shedding of premature larvae, decreasing their survivorship and chances for successful settlement.

\section{MATERIALS AND METHODS}

Five large colonies of Stylophora pistillata (more than $25 \mathrm{~cm}$ in their larger diameter) were carefully brought to the laboratory. All colonies were tested for healthiness, prior to the beginning of the experiments, using similar criteria described by Elgershuizen and De Kruijf (1976). The experiments were conducted during April which is a peak period in the reproduction season of $S$, pistillata (Rinkevich and Loya, 1979a), starting always around $11 \mathrm{a} . \mathrm{m}$. Since there is synchronization in breeding between different branches of the same colony (Rinkevich and Loya, 1979b), it is safe to 
assume homogeneity in the number of potential planulae to be shed from equal-sized branches.

Tests were performed at room temperature in widemouthed glass jars filled with $3 \mathrm{l}$ of unfiltered, aerated sea-water. Branches of approximately equal size $(8 \mathrm{~cm})$ were cut from each colony. Three branches were introduced into each of 6 experimental jars. The comparison between the effects of different oil concentrations was done on branches belonging to the same colony. This procedure was repeated for all 5 colonies. After an hour of acclimation, crude-oil sea-water mixtures were added to the jars in increasing concentrations (see below). A few planulae which were shed in the jars ( 0 to 1 planulae per jar) prior to the oil treatment were removed.

For the preparation of the bioassays, extracts containing water-soluble fractions (WSF) of Iranian crude oil were obtained as follows: Ten parts of Iranian crude oil were slowly stirred by a magnetic stirrer with 1000 parts of sea-water in a glass-stopped Pyrex bottle. After $12 \mathrm{~h}$, stirring was stopped and the solutions allowed to stand for $4 \mathrm{~h}$ before the aqueous phase under the surface of the oil layer was siphoned off into a delivery burette for dispensing to the experimental jars. Since the concentration of oil derived compounds was unknown, this aqueous phase was designated as a $100 \%$ oil extract (or $10.0 \mathrm{ml}^{-1}$; Fig. 1). Lower percentages were obtained by dilution of the aqueous phase with appropriate volumes of sea-water to obtain working concentrations of $0.1,1.0,2.5$, and $5.0 \mathrm{ml}^{-1}$. It should be stressed however, that the real concentrations obtained were much lower, since not all the WSF of the crude oil were dissolved, as shown by Anderson et al. (1974) and Winters et al. (1976). Anderson et al. (1974) tested the concentration of totally dissolved hydrocarbons of several crude oils and fuel oils in WSF of $10 \%$ oil-in-water solutions, after $20 \mathrm{~h}$ of stirring. They found that only 10-20 ppm of the crude oils tested had been dissolved. Similar results were obtained by Winters et al. (1976) on a variety of other crude oils.

\section{RESULTS AND DISCUSSION}

Intact colonies of Stylophora pistillata held in containers in the laboratory reacted by immediate mouthopening after an addition of a few drops of Iranian crude oil to the container. Within a few minutes, numerous larvae were shed through the open mouths of the colonies (Fig. 2). In addition, large quantities of zooxanthellae were expelled to the water. In order to quantify the rate of planulae extrusion at different oil concentrations, the number of extruded planulae within $1 \mathrm{~h}$ and within $6 \mathrm{~h}$ after treatment, was recorded for the 5 tested colonies (Fig. 1).
It is apparent from Figure 1 that, within the first hour of treatment, the highest extrusion occurred in the highest oil concentration. After $6 \mathrm{~h}$ of treatment the distribution of planulae extruded in the different oil concentrations was much more even than within the first hour. The average number of planulae extruded in all oil concentrations, within $1 \mathrm{~h}$ or $6 \mathrm{~h}$ after treatment, was significantly higher than in the control (t-tests, $\mathrm{P}<$ $0.05)$. Thus, the average number of planulae extruded within the first hour of oil treatment was 5.0, 5.7, 10.2, 11.5 , and 27.0 times higher than the control in increasing oil concentrations from 0.1 to $10.0 \mathrm{ml}^{-1}$, respectively. After $6 \mathrm{~h}$ of treatment the average percent of planulae extruded was $3.6,4.6,6.4,7.9$, and 12.4 times higher than the control in the same oil concentrations (Fig. 1).

If no external disturbance exists, Stylophora pistillata sheds its planulae larvae only during night. In

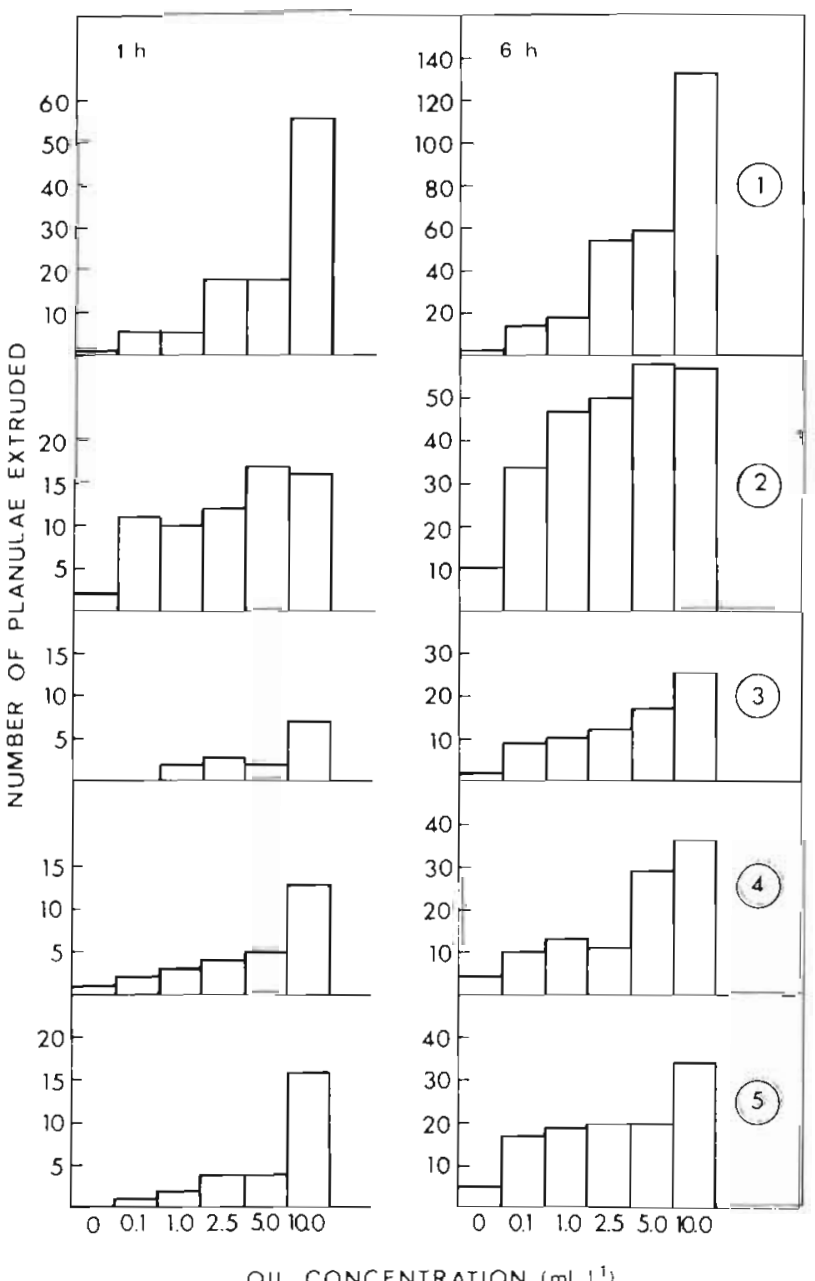

Fig. 1 Stylophora pistillata. Percent extrusion of planulae in different oil concentrations. Histrograms on the left represent percent extrusion within $1 \mathrm{~h}$ of oil treatment. Histrograms on the right represent extrusion within 6 h of oil treatment in the same colony. $0=$ Control. $1-5=$ Colony number 
presence of WSF of crude oil the shedding is immediate, with no connection to time, day or night. This immediate extrusion is untimely and hence, we have termed it 'abortion effect' The mature planula shed by S. pistillata in natural conditions is highly developed. with 6 pairs of complete mesenteries (Halcampoides stage). Although high variability exists in developmental stages of newly-shed planulae of S. pistillata in nature (Rinkevich and Loya, 1979a), it is likely that untimely extrusion of planulae increases the percentage of premature larvae in the reef. Laboratory observations indicate that the settlement of $S$. pistillata planulae occurs within a few hours after shedding and only in the Halcampoides stage (Rinkevich and Loya, 1979a). It may be argued that prematurely extruded larvae (pale planulae without any complete mesenteries or planulae with 2 to 4 couples of complete mesenteries) may complete their development in the water and hence, no harm has been done. However, laboratory observations indicate that the development of immature planulae to the Halcampoides stage usually takes up to $30 \mathrm{~h}$ depending on the stage at which the planulae were shed (Rinkevich and Loya, 1979a). The chances of survival of such planulae are very low, due to the high predation pressure existing in the reef from a wide variety of organisms.

The most significant point, however, in the untimely shedding of planulae is the fact that it coincides with an oil spill. Premature planulae may be shed by corals due to a variety of physical or chemical disturbances (heavy storms or sedimentation, for example). In the laboratory we observed that mouth-opening and shed- ding of planulae occured in response to an increase or decrease of water temperature, or following an addition of a few drops of $70 \%$ alcohol or $4 \%$ formalin to the aquaria. The corals' reaction to oil pollution is therefore similar to any other physical or chemical perturbation. However, since extrusion of planulae occurs during an oil spill, they are expelled into an hostile environment containing WSF of crude oil, in which case their chances of survival and settlement are very low. The coral nature reserve of Eilat may serve as an example of an area which is chronically polluted by oil (at least once per month; Loya, 1975). During these frequent oil spills, which have continued until today, an oil film covers the shallow reef (e.g. lagoon, back reef and reef flat) for several days.

Prolonged and abnormal mouth-opening of scleractinian corals in response to crude oil was previously described (Reimer, 1975a, b) in connection with feeding mechanisms. Reimer (1975a) described feeding reactions in 4 scleractinian corals and a zoanthid coral Palythoa (Reimer, 1975b), elicited by oil floated over the surface water covering the corals (1-4 ml of Marine Diesel or Bunker $C$ oils per litre of sea-water). These reactions were abnormal in the sense that they were exaggerated and lasted up to 17 days of observations. Control colonies remained healthy with their mouths closed throughout 20 days of observation. Reimer (1975a, b) suggested some permanent damage to tissues involved in contraction or perhaps some permanent stimulation of mouth-opening chemoreceptors. She warned that such interference in chemoreceptive processes by oil to corals may have delayed, but long-

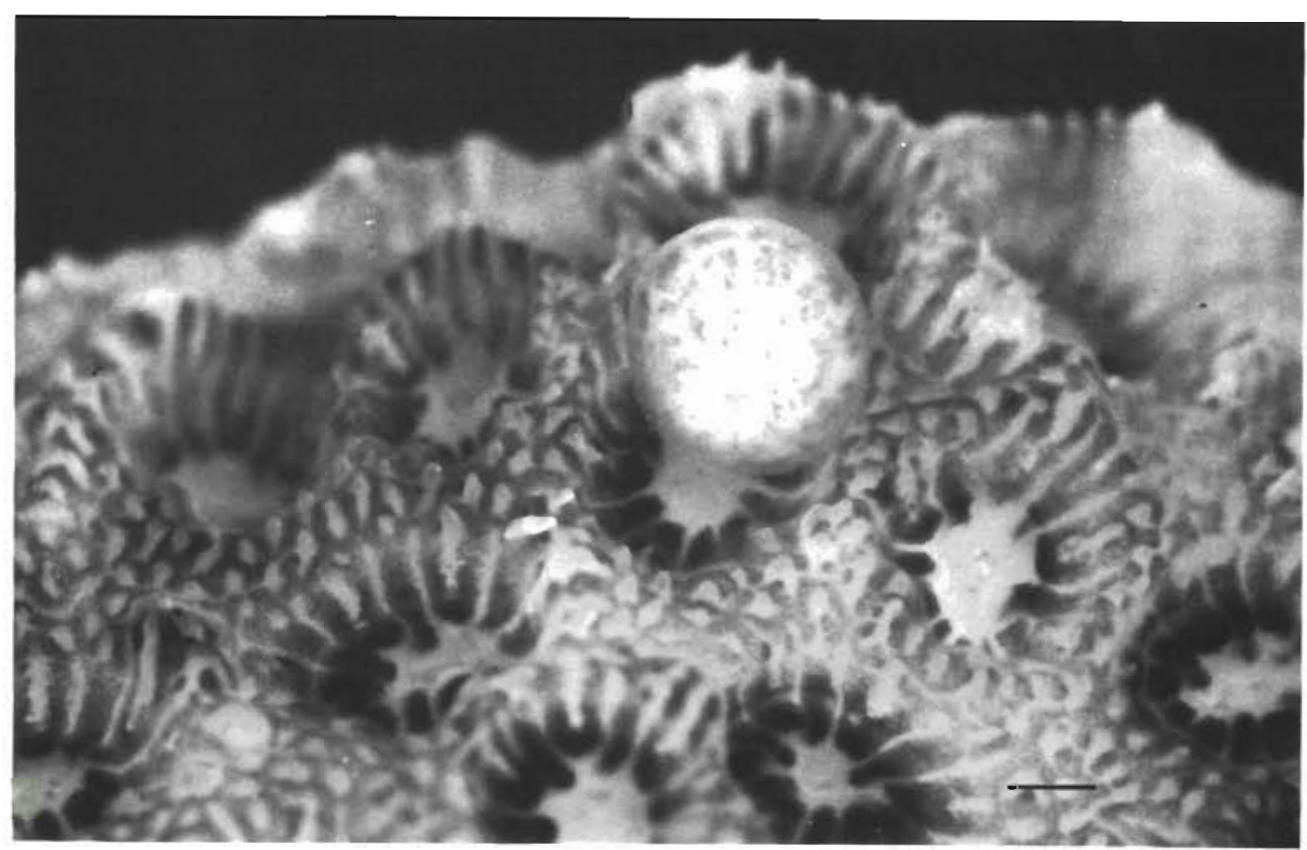

Fig. 2. Stylophora pistillata. Mouth-opening response followed by extrusion of planulae in a colony exposed to Iranian crude oil (scale bar $=0.50 \mathrm{~mm}$ ) 
lasting, effects on the organisms affected and, indirectly, on the communities of which these organisms form part.

Oil pollution decreases significantly the survival chances of many pelagic larvae. Chia (1973) exposed 14 species ( 5 phyla) of pelagic larvae to $0.5 \%$ of No. 2 Diesel oil in sea water and reported that they survived from 3-72 h, except the larvae of an echinoderm, which lived for 8 days. The common symptoms on the contact with oil and before death for most of the larvae were acute contractions of the gut, asynchronization and sluggish beat of the cilia or setae, and occasional violent movement of the body. He suggested that species specificity, in terms of survival of the larvae in oilpolluted water, may be related to the size of the larvae, where larger larvae are expected to survive a longer time. We have observed asynchronization and occasional violent movement in planulae of Stylophora pistillata, even in the lowest oil concentrations. Laboratory experiments on the viability of healthy and mature planulae of $S$. pistillata indicate heavy mortality of planulae with increasing oil concentrations $(0.01$ to $10.0 \mathrm{ml}$ crude oil $\mathrm{l}^{-1}$ sea water, Rinkevich and Loya, 1977). Furthermore, field documentation (Loya, 1976a) combined with laboratory experiments (Rinkevich and Loya, 1977) showed that crude-oil pollution inhibits the settlement of planulae. In chronically-polluted reefs, such as the coral nature reserve of Eilat, almost no colonization of new coral colonies occurs, while high colonization is evident in reef areas free of oil pollution (Loya, 1976a).

In conclusion, it is expected that in other coral species, in which fertilization is internal and planulae are shed, similar reactions and consequences occur due to oil pollution. Larval extrusion due to sublethal concentrations of crude oil $\left(10 \mathrm{ml}^{-1}\right)$ was also reported in the soft coral Heteroxenia fuscescens, after $72 \mathrm{~h}$ of exposure (Cohen et al., 1977), while only a few larvae were shed in control tank experiments. In coral species with external fertilization, we expect expulsion of gametes in response to oil pollution. In such a case, fertilization may be depressed, as has been demonstrated in other marine invertebrates (Renzoni, 1975; Nicol et al., 1977) and furthermore, development of larvae may be prolonged (Nicol et al., 1977; Byrne and Calder, 1977) and hence their chances for survivorship lowered.

Acknowledgements. We thank Mr. A. Shoob for taking the photograph, and Mr. C. Meyer for typing the manuscript. This work was supported by the United States Binational Science Foundation (BSF) Jerusalem, Israel.

\section{LITERATURE CITED}

Anderson, J. W., Neff, J. M., Cox, B. A., Tate, H. E. and Hightower, G. M. (1974). Characteristics of dispersions and water-soluble extracts of crude and refined oils and their toxicity to estuarine crustaceans and fish. Mar. Biol., $27,75-88$.

Byrne, C. J. and Calder, J. A. (1977). Effects of the water soluble fractions of crude, refined and waste oils on the embryonic and larval stages of the Quahog clam Mercenaria sp. Mar. Biol., 40, 225-231.

Chia, Fu-S. (1973). Killing of marine larvae by diesel oil. Mar Pollut. Bull., 4, 29-30.

Cohen, Y., Nissenbaum, A. and Eisler, R. (1977). Effects of Iranian crude oil on the Red Sea Octocoral Heteroxenia fuscescens. Environ. Pollut., 12, 173-185

Elgershuizen, J. H. B. W. and De Kruijf, H. A. M. (1976). Toxicity of crude oils and a dispersant to the stony coral Madracis mirabilis. Mar. Pollut. Bull, 7, 22-25.

Johannes, R. E. (1975). Pollution and degradation of coral reef communities. In E. J. Ferguson Wood and R. E. Johannes (Eds), Tropical Marine Pollution. Elsevier, Amsterdam. pp. $13-51$.

Kinne, O. (Ed.) (in press). Marine Ecology, Vol. V, Ocean Management, Wiley, Chichester.

Loya, Y (1972). Community structure and species diversity of hermatypic corals at Eilat, Red Sea. Mar. Biol., 13, $100-123$.

Loya, Y. (1975). Possible effects of water pollution on the community structure of Red Sea corals. Mar Biol., 29, $177-185$.

Loya, Y (1976a). Recolonization of Red Sea corals affected by natural catastrophes and man-made perturbations. ECOJogy, 57, 278-289.

Loya, Y. (1976b). The Red Sea coral Stylophora pistillata is an $r$ strategist. Nature, Lond., 259, 478-480.

Loya, Y. (1976c). Skeletal regeneration in a Red Sea scleractinian coral population. Nature, Lond., 261, 490-491

Loya, Y. and Rinkevich, B. (in press). Effects of oil pollution on coral reef communities. In D. R. Stoddart and R. W. Grigg (Eds), Coral Reef Ecosystem Under Stress. Academic Press, London.

Nicol, J. A. C., Donahue, W. H., Wang, R. T. and Winters, K (1977). Chemical composition and effects of water extracts of petroleum on eggs of the sand dollar Melitta quinquiesperforata. Mar. Biol., 40, 309-316.

Reimer, A. A. (1975a). Effects of crude oil on corals. Mar. Pollut. Bull., 6, 39-43.

Reimer, A. A. (1975b). Effects of crude oil on the feeding behaviour of the Zoanthid Palythoa variabilis. Environ. Physiol. Biochem., 5, 258-266.

Renzoni, A. (1975). Toxicity of three oils to bivalve gametes and larvae. Mar. Pollut. Bull., 6, 125-128.

Rinkevich, B and Loya, Y (1977). Harmful effects of chronic oil pollution on a Red Sea coral population. In D. L. Taylor (Ed.), Proceedings Third International Coral Reef Symposium II. Geology. University of Miami. pp. 585-591.

Rinkevich, B. and Loya, Y. (1979a). The reproduction of the Red Sea Coral Stylophora pistillata. I. Gonads and planulae. Mar. Ecol. Prog. Ser., 1, in press.

Rinkevich, B. and Loya, Y (1979b). The reproduction of the Red Sea Coral Stylophora pistillata. II. Synchronization in breeding and seasonality of planulae shedding. Mar. Ecol. Prog. Ser., 1 , in press.

Winters, K., O Donnell, R., Batterton, J. C. and Van Baalen, C. (1976). Water soluble components of four fuel oils: Chemical characterization and effects on growth of microalgae. Mar Biol, 36, 269-276. 


\section{Erratum}

Re: Loya and Rinkevich, Mar. Ecol. Prog. Ser., 1, 77-80, 1979

- Page 78, right column, line 13: the word 'percent' should read 'number'. In legend to Figure 1, the words 'percent' in lines 1 to 3 should be omitted.

- Throughout the paper read ' $\mathrm{ml} \mathrm{l}^{-1}$ ', instead of ' $\mathrm{ml}^{-1}$ '. 